\title{
Adequacy of androgen replacement influences bone density response to testosterone in androgen-deficient men
}

\author{
Ashraf Aminorroaya, Sharyn Kelleher, Ann J Conway, Lam P Ly and David J Handelsman \\ Department of Andrology, Concord Hospital \& ANZAC Research Institute, University of Sydney, Sydney, New South Wales 2139, Australia
}

(Correspondence should be addressed to D J Handelsman; Email: djh@anzac.edu.au)

\begin{abstract}
Objective: Androgen deficiency (AD) leads to bone loss and contributes to osteoporotic fractures in men. Although low bone mineral density (BMD) in AD men is improved by testosterone replacement, the responses vary between individuals but the determinants of this variability are not well defined. Design and methods: Retrospective review of dual energy X-ray absorptiometry (DEXA) of the lumbar spine and proximal femur in men with established AD requiring regular androgen replacement therapy (ART). After a DEXA scan all men were treated with testosterone implants $(800 \mathrm{mg}, \sim 6$ month intervals). Patients were classified as having a congenital, childhood, or post-pubertal onset, as well as according to the adequacy of treatment prior to their first DEXA scan as untreated, partially treated or well treated.

Results: Men with AD requiring regular ART ( $n=169$, aged $46.3 \pm 1.1$ years, range $22-84$ years) underwent a DEXA scan prior to being treated with testosterone implants $(800 \mathrm{mg}, \sim 6$ month intervals). In cross-sectional analysis at the time of the first DEXA scan untreated men $(n=24)$ had significantly reduced age-adjusted BMD at all four sites (L1-L4, femoral neck, Ward's triangle and trochanter). Well-treated men $(n=77)$ had significantly better age-adjusted BMD at all four sites compared with those who were partially treated $(n=66)$ or untreated $(n=24)$ with their ageadjusted BMD being normalized. In a longitudinal assessment of men $(n=60)$ who had two or more serial DEXA scans, at the second DEXA scan after a median of 3 years, men who were previously partially treated $(n=19)$ or untreated $(n=11)$ had proportionately greater improvements in BMD, significantly for Ward's triangle $(P=0.025)$ and the trochanter $(P=0.044)$ compared with men $(n=30)$ previously well treated.

Conclusions: The present study demonstrates a positive relationship between adequacy of testosterone replacement and $\mathrm{BMD}$ in men with overt organic $\mathrm{AD}$. Additionally, the $\mathrm{BMD}$ of well-treated $\mathrm{AD}$ men approximates that of age-matched non-AD controls. The greatest BMD gains are made by those who have been either untreated or partially treated, and optimal treatment over time (median 3 years) normalizes BMD to the level expected for healthy men of the same age.
\end{abstract}

European Journal of Endocrinology 152 881-886

\section{Introduction}

Androgen deficiency (AD) causes reduced bone density making it an important and potentially correctable risk factor for osteoporosis and fractures in men (1). Hypogonadism may be present in 5-33\% of men evaluated for vertebral fractures and osteoporosis, and hip fractures in elderly men apparently occur more commonly in the setting of hypogonadism (2). Bone density is decreased following androgen deprivation commencing from birth (3), after childhood cancer treatment (4) or after puberty (5-7). Bone density decreases most strikingly following castration, when bone mineral density (BMD) declines at $3-5 \%$ per annum, especially in the first few years, with a corresponding increase of $4-50 \%$ in prevalence of osteoporotic fractures following complete androgen deprivation $(8-10)$. The extent to which testosterone replacement therapy rectifies deficits in bone density due to less complete $\mathrm{AD}$ remains contentious, with full restoration of bone density to age-matched norms reported in few studies $(11,12)$. Previous studies have suggested potential determinants of this variability in BMD response to testosterone treatment including genetic polymorphisms in the androgen receptor sensitivity (13), the need for long-term treatment $(11,12)$, and the type of hypogonadism or the underlying disease causing hypogonadism $(11,12,14-17)$. The present study aims to evaluate the quality of treatment as a factor influencing BMD response to long-term testosterone replacement therapy. 


\section{Material and methods}

\section{Patients and study design}

All AD men attending the Department of Andrology, Concord Hospital for regular testosterone replacement therapy and who had at least one measurement of lumbar spine and proximal femur BMD by dual energy X-ray absorptiometry (DEXA) were included in this retrospective review of data files. Men with confounding conditions, such as coexisting diseases or using medications known to directly affect the skeleton, were excluded. All of the men described in the paper had classic AD. Patients were classified according to the age of onset of their hypogonadism as congenital, childhood or post-pubertal. The congenital group included idiopathic hypogonadotrophic hypogonadism (IHH) including Kallmann's syndrome, Klinefelter's syndrome, bilateral cryptorchidism or testicular agenesis. Those with childhood onset had been treated with combination chemotherapy with or without cranial radiotherapy for childhood cancers. The post-pubertal onset groups comprised men who had bilateral orchidectomy, pituitary tumours or testicular failure after adolescence. Men with pseudo-hypogonadism (also known as 'late-onset', partial $\mathrm{AD}$ of the ageing male or 'andropause') were not included. AD men were further classified according to the adequacy of testosterone treatment prior to their first DEXA scan as untreated, partially treated and well treated. Adequacy of treatment was defined according to compliance with the recommended dose of testosterone replacement: partial treatment was defined as either long-term treatment with a suboptimal dose or $<1$ year of irregular treatment with an adequate dose prior to the first DEXA scan and 'well treated' was defined as regular adequate treatment with injectable (Sustanon, $250 \mathrm{mg}$ per 2 weeks), or implantable testosterone pellets $(800 \mathrm{mg}$ per 6 months) at the time of the first DEXA scan.

Following the first DEXA scan, patients were treated with testosterone implants and underwent regular BMD measurements at regular $(2-3$ year) intervals. The standard testosterone dose was provided by subdermal implantation of testosterone pellets (four $200 \mathrm{mg}$ testosterone pellets; Organon Australia Pty Ltd), individually titrated (for timing of re-implantation, typically $\sim 6$ monthly) to maintain adequate androgen replacement (18-20). In men with panhypopituitarism, other pituitary hormones (thyroxine and cortisol) were replaced at stable, standard doses if required.

\section{Measurement of BMD}

BMD was measured by DEXA using a Lunar DPX-L3000 densitometer scanner (Madison, WI, USA), with acquisition software version 1.31, at the lumbar spine
(L1-L4) and at the proximal femur. BMD was expressed as raw bone density as well as in standardized deviation scores compared with a young adult (T-score) or agematched (Z-score) reference populations as calculated by the manufacturer's software. The reference population is of US men described in the NHANES study (21). Coefficient of variation for the instrument was $1.5 \%$ in the lumbar spine and $0.8 \%$ in the femoral neck. All 60 subjects with repeat BMD were tested on the same machine.

\section{Statistical analysis}

Data were analysed by repeated measures and factorial ANOVA and ANCOVA and also bivariate correlations and $t$-test as appropriate using SPSS or StatXact software. Body surface area (BSA) was calculated using the Gehan and George formula (22). Body mass index (BMI) was calculated in $\mathrm{kg} / \mathrm{m}^{2}$. Exact $P$ values are reported with a value of $<0.05$ considered as indicating statistical significance. Serial changes in BMD were expressed in percentage changes per year. Data are expressed as means \pm S.E.M. unless stated otherwise.

\section{Results}

There were 167 men (mean age $46.3 \pm 1.1$ years, median 45 years, range 22-84 years) who had at least one DEXA scan. Their onset of hypogonadism was congenital $(n=86,51 \%)$, childhood $(n=18$, $11 \%)$ or post-pubertal $(n=63,38 \%)$. The underlying causes of hypogonadism were IHH including Kallmann's syndrome $(n=40,24 \%)$, Klinefelter's syndrome $(n=24,14 \%)$, cryptorchidism $(n=22,13 \%)$, pituitary tumours $(n=20,12 \%)$, bilateral orchidectomy $(n=19,11 \%)$, post-childhood cancer $(n=18$, $11 \%)$, childhood torsion, mumps orchitis $(n=6,4 \%)$, prolactinoma $(n=6,4 \%)$, haemochromatosis $(n=5$, $3 \%)$, other chromosomal abnormalities $(n=5,3 \%)$ and testicular agenesis $(n=2,1 \%)$. Prior treatment status at the time of the first DEXA scan was untreated $(n=24,14 \%)$, partially treated $(n=66,40 \%)$ and well treated $(n=77,46 \%)$, and these were evenly distributed according to age of onset and diagnosis (Table 1). There were no significant differences between the differing treatment categories regarding age, height, weight, BSA $\left(\mathrm{m}^{2}\right)$ or BMI $\left(\mathrm{kg} / \mathrm{m}^{2}\right)$ (Table 1). None were excluded for confounding conditions, such as coexisting diseases, or for treatment with supplemental calcium, vitamin $\mathrm{D}$ or bisphosphonate, or other drugs known to influence bone density.

\section{Cross-sectional data}

The BMD $\left(\mathrm{g} / \mathrm{cm}^{2}\right)$ at lumbar spine, femoral neck, Ward's triangle, trochanter, and related T-scores 
Table 1 Characteristics and BMD in 167 AD men related to quality of prior testosterone treatment. Data expressed as means \pm S.E.M.

\begin{tabular}{lcccc}
\hline Variables & $\begin{array}{c}\text { Never } \\
\text { treated }\end{array}$ & $\begin{array}{c}\text { Partially } \\
\text { treated }\end{array}$ & $\begin{array}{c}\text { Well } \\
\text { treated }\end{array}$ & $\boldsymbol{P}$ \\
\hline$n$ & 24 & 66 & 77 & \\
Age (years) & $43.8 \pm 2.7$ & $47.9 \pm 1.6$ & $45.7 \pm 1.5$ & 0.42 \\
Height $(\mathrm{cm})$ & $173.6 \pm 2.1$ & $176.2 \pm 1.1$ & $174.9 \pm 1.1$ & 0.51 \\
Weight $(\mathrm{kg})$ & $78.8 \pm 4.1$ & $82.9 \pm 2.0$ & $84.4 \pm 1.1$ & 0.41 \\
BMI $\left(\mathrm{kg} / \mathrm{m}^{2}\right)$ & $25.8 \pm 0.9$ & $26.5 \pm 0.5$ & $27.4 \pm 0.6$ & 0.27 \\
BSA (m $\left.{ }^{2}\right)$ & $1.9 \pm 0.06$ & $2.0 \pm 0.03$ & $2.0 \pm 0.03$ & 0.42 \\
L1-L4 & & & & \\
BMD & $1.115 \pm 0.036$ & $1.109 \pm 0.041$ & $1.171 \pm 0.041$ & 0.510 \\
T-score & $-0.78 \pm 0.26$ & $-0.70 \pm 0.21$ & $0.02 \pm 0.16$ & 0.010 \\
Z-score & $-0.41 \pm 0.27$ & $-0.35 \pm 0.19$ & $0.29 \pm 0.16$ & 0.022 \\
Femoral neck & & & & \\
BMD & $0.943 \pm 0.058$ & $0.905 \pm 0.030$ & $0.971 \pm 0.018$ & 0.234 \\
T-score & $-1.10 \pm 0.24$ & $-0.66 \pm 0.14$ & $-0.36 \pm 0.13$ & 0.025 \\
Z-score & $-0.70 \pm 0.22$ & $-0.41 \pm 0.13$ & $-0.03 \pm 0.13$ & 0.019 \\
Ward's triangle & & & & \\
BMD & $0.847 \pm 0.092$ & $0.744 \pm 0.036$ & $1.019 \pm 0.063$ & 0.050 \\
T-score & $-1.23 \pm 0.32$ & $-0.95 \pm 0.20$ & $-0.65 \pm 0.17$ & 0.234 \\
Z-score & $-0.82 \pm 0.25$ & $-0.50 \pm 0.16$ & $-0.11 \pm 0.13$ & 0.035 \\
Trochanter & & & & \\
BMD & $0.803 \pm 0.084$ & $0.755 \pm 0.029$ & $0.850 \pm 0.026$ & 0.129 \\
T-score & $-0.61 \pm 0.32$ & $-0.77 \pm 0.16$ & $-0.20 \pm 0.15$ & 0.051 \\
Z-score & $-0.37 \pm 0.28$ & $-0.66 \pm 0.15$ & $-0.08 \pm 0.14$ & 0.031 \\
\hline
\end{tabular}

$P$ values from a one-way ANOVA.

(young adult controls) and Z-scores (aged-matched controls) together with anthropometric data according to the adequacy of treatment are listed (Table 1). The prior treatment groups were well balanced for age and anthropometric variables.

Although there were trends for raw bone density at each site towards a higher bone density according to quality of prior treatment, these differences were not statistically significant. When age-adjusted, all sites showed improved bone density according to quality of prior treatment (Table 1). The difference according to quality of prior treatment at all bone sites was unaffected by adjustment for age, height, weight, BMI and BSA by covariance analysis (Table 1), or by type of hypogonadism or underlying disease in multi-way ANOVA.

\section{Longitudinal data}

BMD from a subset $(n=60$, age $43.4 \pm 1.3$ years, range 22-76 years) had a second BMD measurement at a median interval of 3 years (range $1-5$ years) (Table 2).

Previously untreated men experienced greater gains in BMD over time, with a $0.148 \mathrm{~g} / \mathrm{cm}^{2}$ increase in L1-L4 BMD from the first to the second DEXA scan; partially treated men experienced a more modest gain of $0.046 \mathrm{~g} / \mathrm{cm}^{2}$ and the adequately treated men gained $0.046 \mathrm{~g} / \mathrm{cm}^{2} \quad(P<0.001)$ (Fig. 1). At the trochanter site, the gains were $0.19,0.07$ and $0.02 \mathrm{~g} / \mathrm{cm}^{2}$ respectively $(P<0.005)$ (Fig. 2). At Ward's Triangle there was a $0.050 \mathrm{~g} / \mathrm{cm}^{2}$ increase in the untreated group, $0.011 \mathrm{~g} / \mathrm{cm}^{2}$ in those men partially treated and $0.013 \mathrm{~g} / \mathrm{cm}^{2}$ and $0.013 \mathrm{~g} / \mathrm{cm}^{2}$ in men with adequate treatment $(P=0.001)$. At the neck of femur site the gains were 0.031, 0.011 and $0.010 \mathrm{~g} / \mathrm{cm}^{2}$ respectively $(P<0.001)$. The magnitude of improvement was unaffected by adjustment for age, height, weight, BMI and BSA by covariance analysis or by type of hypogonadism or underlying disease in multi-way ANOVA.

Final Z-scores for each of the bone sites indicate no significant differences across the differing treatment

Table 2 Change in bone density between 1st and 2nd DEXA scan according to quality of treatment prior to 1st DEXA scan. Data expressed as means \pm S.E.M.

\begin{tabular}{|c|c|c|c|c|}
\hline & $\begin{array}{l}\text { Never treated } \\
\quad(n=11)\end{array}$ & $\begin{array}{l}\text { Partially treated } \\
\quad(n=19)\end{array}$ & $\begin{array}{l}\text { Well treated } \\
\quad(n=30)\end{array}$ & $\boldsymbol{P}$ \\
\hline \multicolumn{5}{|l|}{ L1-L4 } \\
\hline BMD (\% change/year) & $2.85 \pm 0.82$ & $1.67 \pm 0.38$ & $1.31 \pm 0.84$ & 0.494 \\
\hline Z-score (\% change/year) & $-17.05 \pm 4.52$ & $-0.30 \pm 3.64$ & $-13.41 \pm 25.49$ & 0.975 \\
\hline Z-score (final) & $0.15 \pm 0.51$ & $-0.78 \pm 0.28$ & $-0.20 \pm 0.19$ & 0.121 \\
\hline \multicolumn{5}{|l|}{ Femoral neck } \\
\hline BMD (\% change/year) & $1.76 \pm 1.11$ & $0.42 \pm 0.70$ & $-0.43 \pm 0.71$ & 0.372 \\
\hline Z-score (\% change/year) & $-14.05 \pm 10.19$ & $-11.36 \pm 3.16$ & $18.92 \pm 55.75$ & 0.943 \\
\hline Z-score (final) & $-0.20 \pm 0.34$ & $-0.72 \pm 0.16$ & $0.33 \pm 0.21$ & 0.254 \\
\hline \multicolumn{5}{|l|}{ Ward's triangle } \\
\hline BMD (\% change/year) & $4.35 \pm 2.33$ & $0.47 \pm 0.80$ & $-1.33 \pm 1.03$ & 0.025 \\
\hline Z-score (\% change/year) & $4.55 \pm 9.45$ & $-11.70 \pm 5.99$ & $7.63 \pm 137.33$ & 0.991 \\
\hline Z-score (final) & $-0.40 \pm 0.39$ & $-1.03 \pm 0.22$ & $-0.34 \pm 0.18$ & 0.065 \\
\hline \multicolumn{5}{|l|}{ Trochanter } \\
\hline BMD (\% change/year) & $4.65 \pm 1.27$ & $1.77 \pm 0.88$ & $0.37 \pm 0.81$ & 0.044 \\
\hline Z-score (\% change/year) & $-14.37 \pm 5.54$ & $-18.63 \pm 14.90$ & $8.01 \pm 8.44$ & 0.194 \\
\hline Z-score (final) & $0.18 \pm 0.48$ & $-0.91 \pm 0.22$ & $-0.33 \pm 0.23$ & 0.063 \\
\hline
\end{tabular}

$P$ values from a one-way ANOVA. 

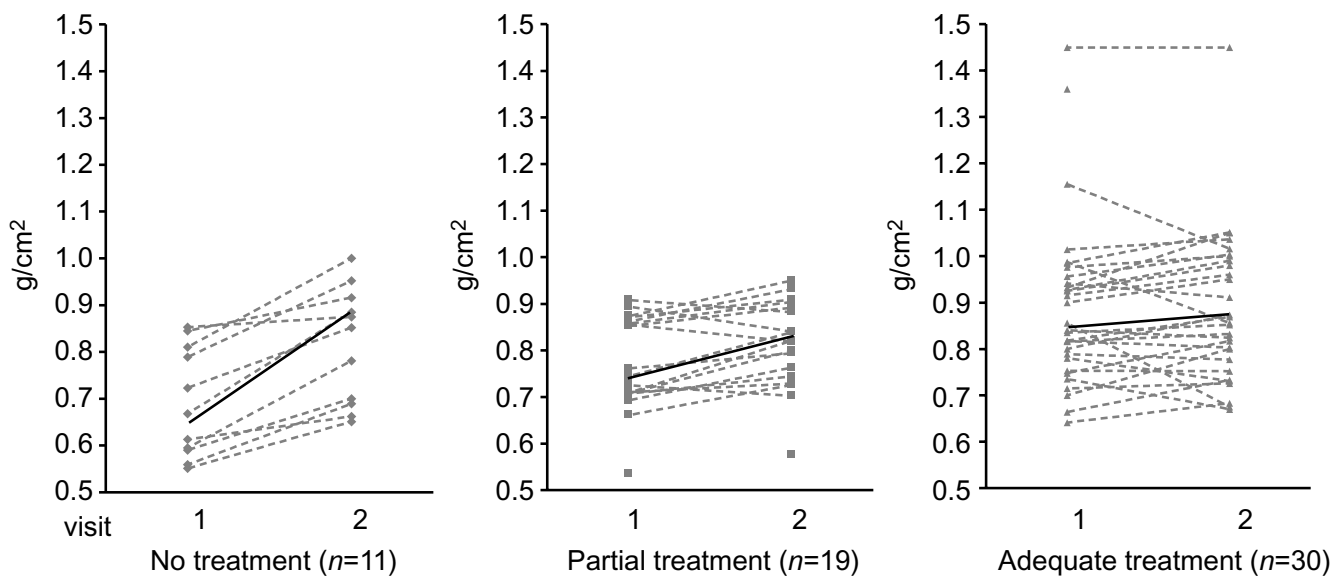

Figure 1 Change in BMD $\left(\mathrm{g} / \mathrm{cm}^{2}\right)$ at trochanter between the first and second visit, depending on treatment at the time of the first BMD.

groups (Table 2), indicating that optimal androgen replacement can overcome the bone mineral deficiency caused by previously being untreated or partially treated (Table 2).

\section{Discussion}

Deficient androgen action, whether due to reduced endogenous testosterone production, hypothalamo-pituitary-testicular axis pathology $(2,6)$ after chronological age of puberty (23) or impaired androgen receptor function (24-26), produces marked bone deficits compared with healthy age-matched eugonadal men. AD reduces not only cancellous and cortical bone mass (5) but also disrupts the macrostructure (27), microarchitecture (28) and biophysical properties (29) of bone. Each of these factors may contribute to the increased fracture risk associated with male hypogonadism $(1,30)$. Recent findings also highlight that a significant proportion of testosterone effects on bone depends upon aromatization to estradiol (31).
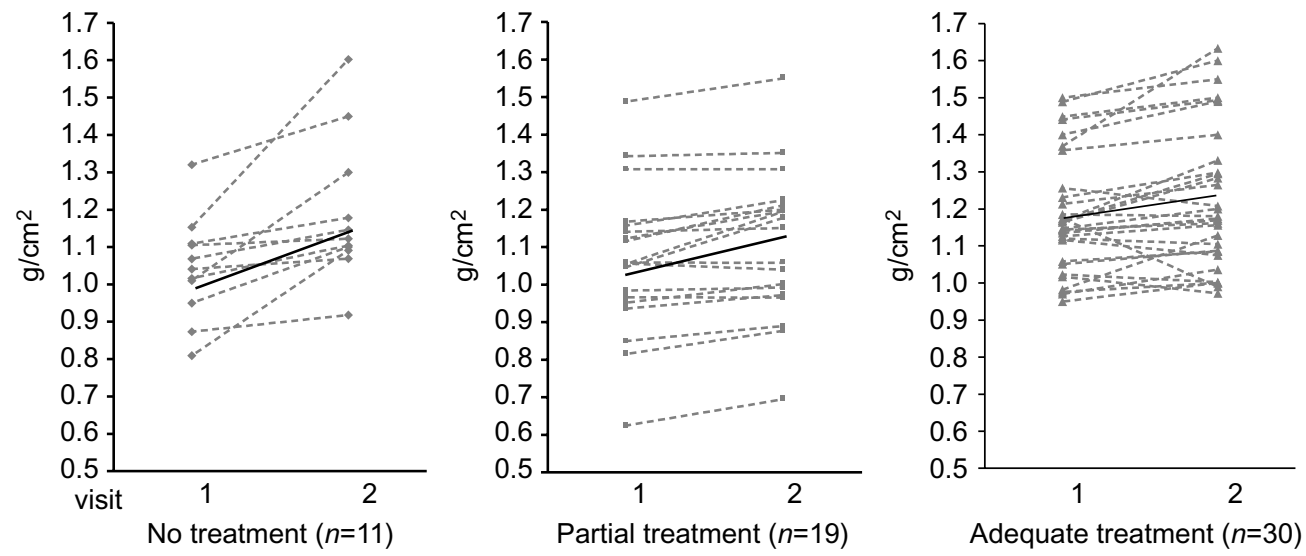

Figure 2 Change in $\mathrm{BMD}\left(\mathrm{g} / \mathrm{cm}^{2}\right)$ at L1-L4 between the first and second visit, depending on treatment at the time of the first BMD.
In the present study we observed that adequate treatment results in BMD that approximates the bone density in healthy non-AD men. Additionally, the poorer the androgen replacement at the time of the initial DEXA scan, the further the resultant BMD is away from age-matched healthy men.

Although testosterone replacement therapy consistently increases bone density in even short-term studies (32-35), normalization of BMD is rarely reported even in long-term studies $(11,12)$. Such a suboptimal outcome may reflect pharmacological limitations of available testosterone products and/or poor adherence to regimens based on them. One major study reported that bone density was only restored to age-matched norms after at least 3 years of effective testosterone treatment (11). However, even among the longer studies most (14-17, $34,36-40)$ but not all (12) still report subnormal bone density persisting even after longer treatment periods. Whether some variations is due to difference in extent of local aromatization of testosterone to estradiol within bone cannot be excluded (41). 
However, this lowered BMD can result in normalization of bone density in well-treated men for the relatively short median duration of 3 years. This suggests that an important determinant of the often suboptimal bone response to testosterone replacement reported previously may be inadequate prior testosterone treatment, largely due to the pharmacological limitations and inconvenience of the available testosterone products. Our findings on the bone density benefits of sustained, adequate treatment are consistent with findings that $\mathrm{AD}$ thalassaemic adolescents taking regular testosterone treatment had higher BMD than others whose testosterone treatment was irregular $(42,43)$. In most previous longer ( $>3$ year) studies $(14-17,34$, 36-40), however, testosterone was administered as injectable testosterone esters at doses $<100 \mathrm{mg}$ per week, the standard for effective testosterone replacement $(34,44,45)$. The pharmacokinetic limitations of the available injectable testosterone esters dictate that stable blood testosterone concentrations in the physiological range are achieved with injections at the rate of $100 \mathrm{mg}$ per week, ideally with actual $100 \mathrm{mg}$ injections each week $(34,44,45)$. In practice, however, many patients do not accept regular weekly injections and this regimen is often relaxed to $200 \mathrm{mg}$ every 2 weeks, although such regimens still often encounter significant non-adherence to a regular schedule (15). Maintaining the same weekly dosing at longer (3 or more weeks) inter-injection intervals leads to increasingly extreme fluctuations in blood testosterone levels and, consequentially, in mood and behavioural swings. This ill-sustained androgen replacement is also reflected in the escape of blood luteinizing hormone from suppression in men with hypergonadotrophic hypogonadism (44).

These considerations suggest that suboptimal testosterone replacement dosage may be an overlooked determinant of previously reported inadequate bone density response to testosterone rather than unexplained independent bone effects of the underlying disorders causing hypogonadism $(14,46)$. Recognizing the importance of sustaining adequate testosterone treatment over prolonged periods may also lead to reconsideration of claims that bone deficits occurring in adolescence (prior to acquisition of peak bone mass (47)) may not be correctable in the light of more effective treatment.

Limitation of this study include its retrospective design. Although the data were collected prospectively according to a standard clinic schedule of bone density scans at 2-3 year intervals, incomplete recruitment or participation may have influenced the findings. It must be acknowledged that there are limitations in this type of retrospective review, and systematic studies of the long-term bone effects of more acceptable testosterone regimens with improved adherence to optimal dosing schedules will be of interest. Another limitation is the lack of an untreated or a placebo-treated control group. In theory such untreated men would make it easier to evaluate the effects of passage of time and other non-hormonal factors on serial bone density; however, ethical constraints, because a treatment of proven benefit is available, preclude such controls. A further limitation on the interpretation of this study is that by excluding older men with so-called 'andropause', the present findings may not be applicable to such men.

We conclude that testosterone replacement therapy with an adequate dosage administered consistently can normalize the bone deficit of $\mathrm{AD}$ men, regardless of type or cause of AD. Suboptimal testosterone dose and/or compliance may compromise the restoration to age-specific bone density norms.

\section{Acknowledgements}

A A was supported by a research fellowship awarded by the Isfahan University of Medical Sciences, Iran.

\section{References}

1 Seeman E, Melton LJ, O’Fallon WM \& Riggs BL. Risk factors for spinal osteoporosis in men. American Journal of Medicine 1983 $75977-983$.

2 Orwoll ES \& Klein RF. Osteoporosis in men. Endocrine Reviews $19951687-116$

3 Breuil V \& Euller-Ziegler L. Gonadal dysgenesis and bone metabolism. Joint, Bone, Spine: Revue du Rhumatisme 200168 26-33.

4 Arikoski P, Voutilainen R \& Kroger H. Bone mineral density in long-term survivors of childhood cancer. Journal of Pediatric Endocrinology and Metabolism 200316 (Suppl 2) 343-353.

5 Finkelstein JS, Klibanski A, Neer RM, Greenspan SL, Rosenthal DI \& Crowley WF Jr. Osteoporosis in men with idiopathic hypogonadotropic hypogonadism. Annals of Internal Medicine $1987 \mathbf{1 0 6}$ 354-361.

6 Bilezikian JP. Osteoporosis in men. Journal of Clinical Endocrinology and Metabolism $1999 \mathbf{8 4} 3431-3434$.

7 Seeman E. Osteoporosis in men: epidemiology, pathophysiology, and treatment possibilities. American Journal of Medicine 1993 $9522 \mathrm{~S}-28 \mathrm{~S}$.

8 Stepan JJ, Lachman M, Zverina J, Pacovsky V \& Baylink DJ. Castrated men exhibit bone loss: effect of calcitonin treatment on biochemical indices of bone remodeling. Journal of Clinical Endocrinology and Metabolism $198969523-527$.

9 Daniell HW. Osteoporosis due to androgen deprivation therapy in men with prostate cancer. Urology 200158 101-107.

10 Ross RW \& Small EJ. Osteoporosis in men treated with androgen deprivation therapy for prostate cancer. Journal of Urology 2002 167 1952-1956.

11 Behre HM, Kliesch S, Leifke E, Link TM \& Nieschlag E. Long-term effect of testosterone therapy on bone mineral density in hypogonadal men. Journal of Clinical Endocrinology and Metabolism 1997 82 2386-2390.

12 Zacharin MR, Pua J \& Kanumakala S. Bone mineral density outcomes following long-term treatment with subcutaneous testosterone pellet implants in male hypogonadism. Clinical Endocrinology 200358 691-695.

13 Zitzmann M, Brune M, Kornmann B, Gromoll J, Junker R \& Nieschlag E. The CAG repeat polymorphism in the androgen receptor gene affects bone density and bone metabolism in healthy males. Clinical Endocrinology 2001 55 649-657. 
14 Wong FH, Pun KK \& Wang C. Loss of bone mass in patients with Klinefelter's syndrome despite sufficient testosterone replacement. Osteoporosis International 19933 3-7.

15 Van Den Bergh JP, Hermus AR, Spruyt AI, Sweep CG, Corstens FH \& Smals AG. Bone mineral density and quantitative ultrasound parameters in patients with Klinefelter's syndrome after longterm testosterone substitution. Osteoporosis International 2001 $1255-62$

16 Medras M, Jankowska EA \& Rogucka E. Effects of long-term testosterone substitutive therapy on bone mineral content in men with hypergonadotrophic hypogonadism. Andrologia 200133 47-52.

17 De Rosa M, Paesano L, Nuzzo V, Zarrilli S, Del Puente A, Oriente P \& Lupoli G. Bone mineral density and bone markers in hypogonadotropic and hypergonadotropic hypogonadal men after prolonged testosterone treatment. Journal of Endocrinological Investigation 200124 246-252.

18 Handelsman DJ, Conway AJ \& Boylan LM. Pharmacokinetics and pharmacodynamics of testosterone pellets in man. Journal of Clinical Endocrinology and Metabolism 199071 216-222.

19 Handelsman DJ, Mackey MA, Howe C, Turner L \& Conway AJ Analysis of testosterone implants for androgen replacement therapy. Clinical Endocrinology $199747311-316$.

20 Handelsman DJ. Clinical pharmacology of testosterone pellet implants. In Testosterone: Action Deficiency Substitution, pp 349-364. Eds E Nieschlag \& HM Behre. Berlin: Springer, 1998.

21 Looker AC, Wahner HW, Dunn WL, Calvo MS, Harris TB, Heyse SP, Johnston CC Jr \& Lindsay R. Updated data on proximal femur bone mineral levels of US adults. Osteoporosis International $19988468-489$

22 Bailey BJ \& Briars GL. Estimating the surface area of the human body. Statistics in Medicine 199615 1325-1332.

23 Nanao K, Tsuchiya Y, Kotoh S \& Hasegawa Y. Low vertebral cancellous bone density in peripubertal girls with Turner's syndrome and boys with hypogonadism. Journal of Pediatric Endocrinology and Metabolism 200215 1537-1542.

24 Soule SG, Conway G, Prelevic GM, Prentice M, Ginsburg J \& Jacobs HS. Osteopenia as a feature of the androgen insensitivity syndrome. Clinical Endocrinology $199543671-675$.

25 Munoz-Torres M, Jodar E, Quesada M \& Escobar-Jimenez F. Bone mass in androgen-insensitivity syndrome: response to hormonal replacement therapy. Calcified Tissue International $1995 \mathbf{5 7}$ 94-96.

26 Marcus R, Leary D, Schneider DL, Shane E, Favus M \& Quigley CA. The contribution of testosterone to skeletal development and maintenance: lessons from the androgen insensitivity syndrome. Journal of Clinical Endocrinology and Metabolism $2000 \mathbf{8 5}$ $1032-1037$

27 Seeman E. Invited review: Pathogenesis of osteoporosis. Journal of Applied Physiology 200395 2142-2151.

28 Benito M, Gomberg B, Wehrli FW, Weening RH, Zemel B, Wright AC, Song HK, Cucchiara A \& Snyder PJ. Deterioration of trabecular architecture in hypogonadal men. Journal of Clinical Endocrinology and Metabolism 200388 1497-1502.

29 Zitzmann M, Brune M, Vieth V \& Nieschlag E. Monitoring bone density in hypogonadal men by quantitative phalangeal ultrasound. Bone $200231422-429$

30 Seeman E. Unresolved issues in osteoporosis in men. Reviews in Endocrine and Metabolic Disorders 20012 45-64.

31 Vanderschueren D, Vandenput L, Boonen S, Lindberg MK, Bouillon R \& Ohlsson C. Androgens and bone. Endocrine Reviews $200425389-425$.

32 Katznelson L, Finkelstein JS, Schoenfeld DA, Rosenthal DI, Anderson EJ \& Klibanski A. Increase in bone density and lean body mass during testosterone administration in men with acquired hypogonadism. Journal of Clinical Endocrinology and Metabolism $1996 \mathbf{8 1} 4358-4365$.
33 Isaia G, Mussetta M, Pecchio F, Sciolla A, Di Stefano M \& Molinatti GM. Effect of testosterone on bone in hypogonadal males. Maturitas 199215 47-51.

34 Snyder PJ, Peachey H, Berlin JA, Hannoush P, Haddad G, Dlewati A, Santanna J, Loh L, Lenrow DA, Holmes JH, Kapoor SC, Atkinson LE \& Strom BL. Effects of testosterone replacement in hypogonadal men. Journal of Clinical Endocrinology and Metabolism 200085 2670-2677.

35 Wang C, Swerdloff RS, Iranmanesh A, Dobs A, Snyder PJ, Cunningham G, Matsumoto AM, Weber T \& Berman N. Effects of transdermal testosterone gel on bone turnover markers and bone mineral density in hypogonadal men. Clinical Endocrinology $200154739-750$.

36 Ishizaka K, Suzuki M, Kageyama Y, Kihara K \& Yoshida K. Bone mineral density in hypogonadal men remains low after long-term testosterone replacement. Asian Journal of Andrology $2002 \mathbf{4}$ 117-121.

37 Canale D, Vignali E, Golia F, Martino E, Pinchera A \& Marcocci C. Effects of hormonal replacement treatment on bone mineral density and metabolism in hypogonadal patients. Molecular and Cellular Endocrinology $2000 \mathbf{1 6 1} 47-51$

38 Guo CY, Jones TH \& Eastell R. Treatment of isolated hypogonadotropic hypogonadism effect on bone mineral density and bone turnover. Journal of Clinical Endocrinology and Metabolism 1997 $82658-665$.

39 Devogelaer JP, De Cooman S \& Nagant De Deuxchaisnes C. Low bone mass in hypogonadal males. Effect of testosterone substitution therapy, a densitometric study. Maturitas 199215 17-23.

40 Kubler A, Schulz G, Cordes U, Beyer J \& Krause U. The influence of testosterone substitution on bone mineral density in patients with Klinefelter's syndrome. Experimental and Clinical Endocrinology $1992100129-132$.

41 Khosla S, Melton LJ 3rd \& Riggs BL. Clinical review 144: Estrogen and the male skeleton. Journal of Clinical Endocrinology and Metabolism 200287 1443-1450.

42 Anapliotou ML, Kastanias IT, Psara P, Evangelou EA, Liparaki M \& Dimitriou P. The contribution of hypogonadism to the development of osteoporosis in thalassaemia major: new therapeutic approaches. Clinical Endocrinology 199542 279-287.

43 Lasco A, Morabito N, Gaudio A, Buemi M, Wasniewska M \& Frisina N. Effects of hormonal replacement therapy on bone metabolism in young adults with beta-thalassemia major. Osteoporosis International $200112570-575$.

44 Snyder PJ \& Lawrence DA. Treatment of male hypogonadism with testosterone enanthate. Journal of Clinical Endocrinology and Metabolism 198051 1335-1339.

45 Behre HM \& Nieschlag E. Comparative pharmacokinetics of testosterone esters. In Testosterone: Action Deficiency Substitution, pp 329-348. Eds E Nieschlag \& HM Behre. Berlin: Springer, 1998.

46 Finkelstein JS, Klibanski A, Neer RM, Doppelt SH, Rosenthal DI, Segre GV \& Crowley WF. Increases in bone density during treatment of men with idiopathic hypogonadotropic hypogonadism. Journal of Clinical Endocrinology and Metabolism 198969 $776-783$.

47 Lu PW, Briody JN, Ogle GD, Morley K, Humphries IR, Allen J, Howman-Giles R, Sillence D \& Cowell CT. Bone mineral density of total body, spine, and femoral neck in children and young adults: a cross-sectional and longitudinal study. Journal of Bone and Mineral Research 19949 1451-1458.

Received 26 October 2004

Accepted 8 March 2005 